\title{
Rupture of umbilical cord at birth: An unusual case of acute neonatal haemorrhage
}

\author{
Laura De Petris*, Maria Rita Sabatini and Ermanno Ruffini \\ Maternal- Infant Unit, Paediatrics and Neonatology Division, C. G. Mazzoni Hospital, Ascoli Piceno, Italy
}

\begin{abstract}
Stillbirth is a major obstetric complication. There are at least 3.2 million stillbirths worldwide every year. Umbilical cord abnormalities account for 3.4-15\% of stillbirths. Among these, rupture of umbilical vessel is estimated to occur in about 1:6.000 deliveries and when rupture does occur in utero, the fetal mortality rate is of approximately $50 \%$.

A 43-year-old eleventh gravida was admitted to the hospital at 41 weeks of gestational age. Continuous fetal heart rate monitoring was regular until the delivery. Although the fetus was delivered with no traction and no signs of fetal distress were recorded, the fetus appeared with complete severance of all the three umbilical vessels at the fetus end.

A prompt surgery was necessary to stop the acute haemorrhage of the infant that was in good clinical conditions although the active bleeding from the umbilical vessels.

Our case may represent a previously undocumented case of neonatal haemorrhage at birth caused by a rupture of umbilical vessels in an apparently normal umbilical cord, and not associated with no fetal co-morbidity or other cord or placenta abnormalities.

The issue of aberrant umbilical cord as a cause of fetal harm and stillbirth is unaddressed in modern reproductive care and identification of umbilical cord abnormalities is still a demanding problem in obstetrics.
\end{abstract}

\section{Clinical Case}

A 43-year-old eleventh gravida was admitted to the Maternal Infant Department at 41 weeks of gestational age for polyhydramnios.

The course of the pregnancy was normal till the 30 weeks of gestational age. Afterwards the women underwent therapy with antithrombotic for the venous stagnation in the legs and with antibiotics for urinary tract infection.

Maternal antibodies for TORCH complex - Toxoplasma gondii, Rubella virus, Cytomegalovirus, Herpes simplex virus- and for hepatitis virus $\mathrm{C}$ and $\mathrm{C}$, Human immunodeficiency virus and syphilis were negative for active infection. All the ultrasounds tests performed during the pregnancy revealed normal findings of fetus, placenta and umbilical cord.

Onset of labor was spontaneous as well the membrane rupture with appearance of large amount of clear amniotic fluid. Fetal heart tones remained strong and regular until the delivery that occurred after two hours from the onset of labor and no signs of fetal distress were recorded. The fetal head engaged in the left occiput transverse position and afterwards it rotated easily to right occiput anterior position until the cervix was fully dilatated. One umbilical cord knot was around the fetal neck, however the fetus was delivered with no traction. During the expulsion phase of the labor a complete spontaneous severance of all the three umbilical vessels occurred at fetus side while umbilical cord was regularly attached to the placenta side.

No appearance of abnormal vaginal bleeding was noted during the labor or during the extraction phase of the fetus. At birth the infant was in good clinical condition although he presented active bleeding from the umbilical vessels. The Apgar score was 9 at 1st and 5th minute. A prompt surgery was necessary to stop the ongoing acute haemorrhage.

Examination of the placenta revealed a normal cord insertion with 2 arteries and 1 vein. The length of umbilical cord was normal as well the amount of Wharton gelatine even if several areas of less strength were noted along the length of the cord. The following clinical course of the baby was normal. No infection was detected, the neonate made a full recovery from the accident and was discharged from the hospital at third day of life.

The frequency of cord accidents is not truly known. A review of stillbirths suggests that umbilical cord accident have at least an incidence of 1.5 stillbirths/1000 births [1-4].

Umbilical cord abnormalities are numerous, ranging from false knots, which have no clinical significance, to vasa previa, which often leads to fetal death $[5,6]$. Among the abnormalities the rupture of the cord is not uncommon but significantly underreported [7].

${ }^{\star}$ Correspondence to: Laura De Petris, Maternal- Infant Unit, Paediatrics and Neonatology Division, C.G. Mazzoni Hospital, Via degli Iris, 4, 63100 Ascoli Piceno, Italy, Tel/Fax: +390736358266; E-mail: lauradepetris@hotmail.com

Key words: acute neonatal haemorrhage, prenatal diagnosis, aberrant fetal vessel, umbilical cord accident

Received: October 22, 2018; Accepted: October 27, 2018; Published: October 30, 2018 
A review of the literature reveals that most often ruptures occur at the placental side, where the cord tends to be the weakest and that cord rupture is often associated with other abnormalities such as hematoma, underwater births, short cord, ascending cord inflammation prior to the time of delivery and velamentous cord insertions $[7,8]$.

According to the reasons, umbilical cords rupture can be associated with normal or adverse perinatal outcomes leading to stillbirth, asphyxia, fetal distress, and neurologic damage. When rupture does occur in utero signs of fetal distress appear and fetal mortality rate is approximately $50 \%$ [8-10].

In our case the pregnancy course was physiological, the fetal tracing showed normal fetal heart rate during all the stages of labor. We did not have the opportunity to perform the histological examination of the umbilical cord. However, at the gross inspection the umbilical cord was normal and the placenta did not show any gross abnormalities. In addition, the fetal growth was regular during all the pregnancy and thus we did not have any significant factors to believe that the histological exam of the placenta and the cord could show any abnormalities.

The massive acute haemorrhage at birth was not fatal for the infant, maybe because occurred during the expulsion phase of the labor, or because the surgery was prompt and the highly developed media of the arteria cord is capable of extraordinary vasospasm.

To our knowledge our report may represent a previously undocumented case of neonatal hemorrhage at birth caused by a rupture of umbilical vessels in an apparently normal umbilical cord, and not associated with fetal co-morbidity or other cord or placenta abnormalities.

We can hypothesize that in our case the rupture of aberrant fetal vessels occurred during the expulsion phase of the labor because the fetal heart rate tracing did not show any signs of fetal distress during all the labor. However, despite the ultrasonography and Doppler flow measurements were normal during the prenatal care, we cannot exclude the presence of microscopical umbilical cord abnormalities because these techniques are often not able to identify them.
The absence nowadays of safe and specific techniques capable to detect umbilical cord problems during the prenatal care and during the three stages of labor, makes the issue of aberrant fetal vessels still not completely addressed in modern reproductive care.

The surveillance and timely identification of umbilical cord abnormalities as a cause of fetal damage and still birth is mandatory to reduce perinatal mortality.

\section{Financial Disclosure}

The authors did not report any potential conflicts of interest.

\section{References}

1. Stanton C, Lawn JE, Rahman H, Wilczynska-Ketende K, Hill K (2006) Stillbirth rates delivering estimates in 190 countries. Lancet 367:1487-1494. [Crossref]

2. MacDorman MF, Kirmeyer S (1996) Fetal and Perinatal Mortality, United States, 2005. Natl Vital Stat Rep 57: 1-20.

3. Korteweg FJ, Gordijn SJ, Timmer A, Erwich JJ, Bergman KA, et al. (2006) The Tulip classification of perinatal mortality: introduction and multidisciplinary inter-rater agreement. BJOG 113: 393-340. [Crossref]

4. Collins JH (2002) Umbilical cord accidents: human studies. Semin Perinatol 26: 79-82. [Crossref]

5. Reddy UM, Goldenberg R, Silver R, Smith GC, Pauli RM, et al. (2009) Stillbirth Classification-Developing an International Consensus for Research: Executive Summary of a National Institute of Child Health and Human Development Workshop. Obstet Gynecol 114: 901-914. [Crossref]

6. Naidu M, Nama V, Karoshi M, Kakumani V, Worth R (2007) Umbilical cord rupture a case report and review of literature. Int J Fertil Womens Med 52:107-110. [Crossref]

7. Collins JH, Collins CL, Collins CC (2010) Umbilical cord accidents. The Pregnancy Institute

8. Sviggum HP, Gill LA, Traynor KD (2016) Velamentous Umbilical Cord Insertion and Ruptured Fetal Vessel: A Cause of Fetal-Maternal Hemorrhage: A Case Report. $J$ Reprod Med 61: 598-600. [Crossref]

9. Krakowiak P, Smith EN, de Bruyn G, Lydon-Rochelle MT (2004) Risk factors and outcomes associated with a short umbilical cord. Obstet Gynecol 103: 119-127. [Crossref]

10. Walker C, Ward J (2009) Intrapartum Umbilical Cord Rupture. Obstet Gynecol 113: $552-554$.

Copyright: (C2018 Petris LD. This is an open-access article distributed under the terms of the Creative Commons Attribution License, which permits unrestricted use, distribution, and reproduction in any medium, provided the original author and source are credited. 